\title{
Optimizing Building Envelopes’ Performance by Using Photovoltaic Cells
}

\author{
Hussain Hendi Alzoubi* \\ The University of Michigan, Ann Arbor, MI, 48109
}

This study seeks the integrity and the optimality of building envelopes' performance. It focuses on the transparent parts of buildings' façades; specifically, the windows and their shading devices. It suggests a new system of utilizing solar energy while keeping optimal solutions for indoor daylighting. It employs the shading devices on windows for producing electrical power by using photovoltaic cells. To achieve the optimality for lighting and energy production, blinds with angles from zero to ninety degrees were tested in an actual physical model. This model was used to find the correlation between the blinds' angles and the illuminance level at different distances from the window. Computational methods were used to examine the photovoltaic performance for each blinds' angle.

The mathematical equations resulted from the optimization process were coded using Java programming language to enable the future users to deal with generic locations of buildings. Furthermore, the results of the study's experiments were employed to create a blinds' control system. This system controls the blinds' movements according to the sun position and workplane illuminance level.

\section{Nomenclature}

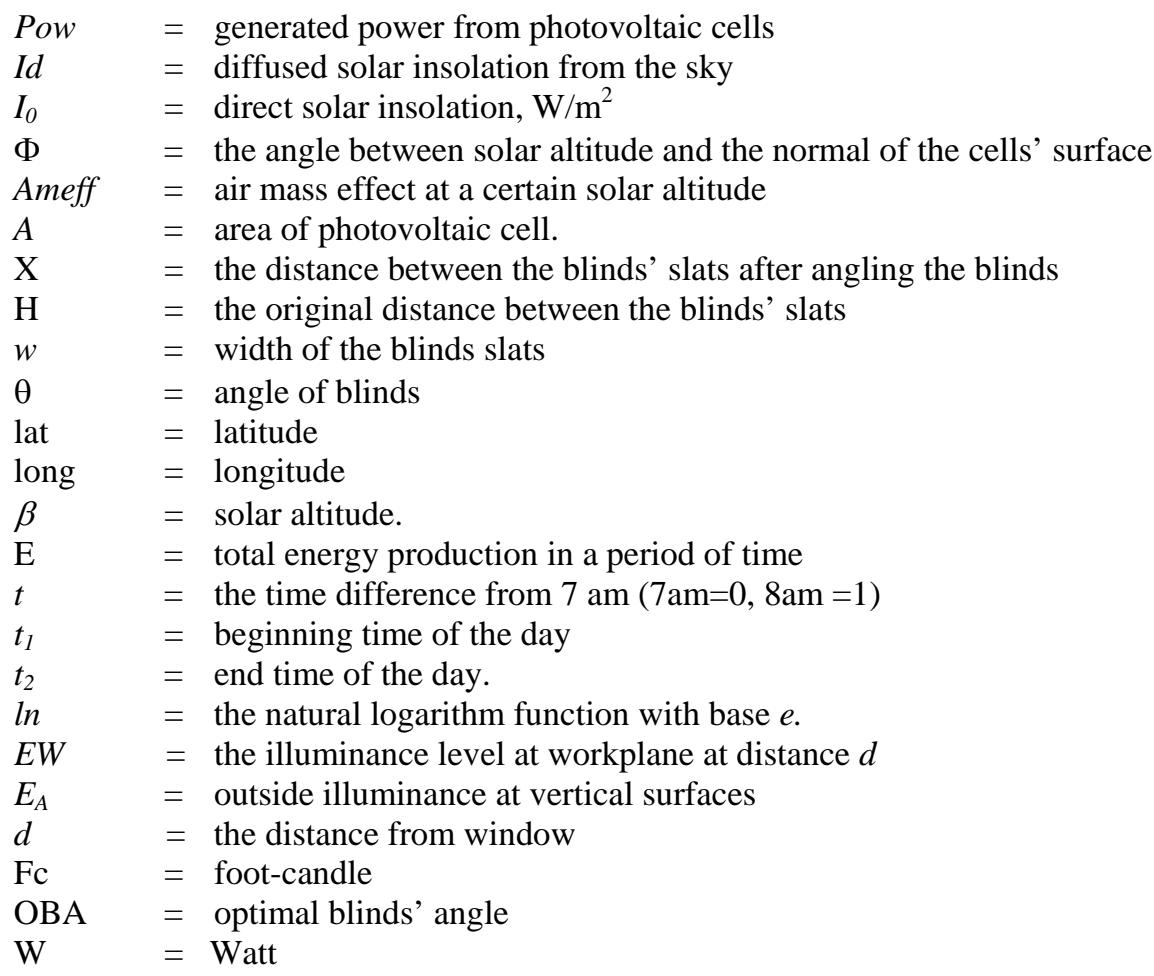

* PhD candidate, Doctoral Program in Architecture, 2000 Bonisteel, MI, 48109, Email: alzoubih@umich.edu 


\section{Introduction}

B uilding envelopes are normally designed for many physical purposes; in this study, the major concern is to enhance the performance of building facades in terms of solar energy and indoor daylight. The most active parts of building skins are the windows; a good window design is not an easy task if we consider the integrity between daylighting and energy consumption in buildings. It is essential that the solar energy projected on windows be controlled and utilized effectively.

As the illuminance level on the workplane should not exceed the standard limits, and only a small portion of the solar energy is needed for indoor daylighting, there should be some effective ways to utilize the entire solar energy projected on windows.

This study proposes placing moveable blinds on windows to act as shading devices and installing photovoltaic cells on the slats of these blinds to absorb the remainder solar energy and convert it into electrical power.

To achieve this goal, this study seeks optimal blinds' angles that 1) maintain the indoor illuminance level within the acceptable range for human visual comfort; 2) maximize the energy production from the photovoltaic cells placed on the blinds; 3) minimize the heat gain in summer and maximizing it in winter.

To trap all the solar energy falling on windows, this study suggests that the blinds be located between two glass layers. This solution helps control the amount of heat gain in summer and winter.

\section{The influential treatments}

The previous studies about solar energy and blinds explored the strong mathematical relation between the blinds' angle and the illuminance level inside the space ${ }^{1}$. Likewise, most building envelopes' parameters have been studied to find out their effect on the heat gain in buildings. Glass conductivity, window size, glass absorbance, wall thickness, are examples of variables that have been studied so far $^{2}$. Furthermore, new methods for self-responsive thermo tropic glass have been presented to reduce the solar radiation in summer ${ }^{3}$.

In this study, the focus is on the integrity between solar energy and daylight; therefore only the interdependent variables are tested to find the correlation between daylight and energy production. The blinds' angle is the most important treatment that affects simultaneously the three major dependent variables, the heat gain, the daylight, and the energy production from the photovoltaic cells placed on the blinds.

\section{The theme of measuring blinds' angles}

The radiation of lighting and heat happens among surfaces; in buildings, the main source of radiation is the windows. Using blinds as shading devices on windows changes the conditions of radiation and creates a new geometrical situation. This section explores the importance of blinds' angles measurements for lighting, heat gain, and energy production from photovoltaic cells placed on the blinds.

\section{A. Blinds' angles and photovoltaic cells}

Refer to Fig. 1, the angle of the blinds $\theta$ and the incident angle $\Phi$ have a sum of $90, \theta+\Phi=90$ and $\Phi=90-\theta$. The generated energy from the photovoltaic cells placed on the blinds is fully related to the angle between the solar altitude and the normal of the blinds' surface based on the following equation:

$$
\operatorname{Pow}\left(\mathrm{W} / \mathrm{m}^{2}\right)=0.18\left[I d+\text { Ameff } I_{0} A \cos (\Phi)\right]
$$

As $\Phi=90$ - $\theta$, then any change in the blinds' angle $\theta$ changes the value of $\Phi$ and eventually affects the generated power from the photovoltaic cells. In addition, blinds' angles affect the areas of photovoltaic cells that might be obstructed by the upper slats of the blinds. Figure 2 shows the relation between the blinds' angles and the maximum solar profile angle that keeps the photocells uncovered by the upper slats.

\footnotetext{
${ }^{1}$ Kwang-Wook Park , Andreas K.Athienitis, "Workplane Illuminance Prediction Method for Daylighting Control Systems," Solar Energy, Vol. 75, 2003, pp. 277 -284.

${ }^{2}$ Cheol-Soo Park, Godfried Augenbroe, Tahar Messadi, "Daylighting Optimization in Smart Façade Systems," Eighth International IBPSA Conference, Eindhoven, Netherlands August 11-14, 2003, pp. 1001-1008.

${ }^{3}$ Takashi Inoue, "Solar Shading and Daylighting by Means of Autonomous Responsive Dimming Glass: practical applications,” Energy and buildings, Vol. 35, 2003, pp. 463-471
} 


\section{B. Blinds' angles and heat gain}

Figure 3 shows the distance $\mathrm{X}$ that is wholly dependent on the blinds' angle $\theta$. If this angle is zero then the value of $\mathrm{X}$ will be the highest and equal to the original distance between the blinds' slats. When the blinds' angle approaches $90^{\circ}$ the value of $\mathrm{X}$ approaches zero. The relation between the blinds' angle $\theta$ and the value of $\mathrm{x}$ is given by:

$$
\mathrm{X}=\mathrm{H}-2 \mathrm{w} \sin (\theta)
$$

The radiating heat through the blinds depends on the distance between the slats and the reflection of solar radiation from the slats going into the space. When the blinds' angle gets changed, the value of $X$ gets changed as well. This gives specific thermal conditions for every blind's angle and eventually affects the amount of heat gain for each angle.

In this study, heat gain is not the only concern; rather, the study focuses on the interconnectivity among heat gain, energy production from the photovoltaic cells, and the indoor light level. Changing blinds' angles to reduce the heat gain should take into account the effect on daylighting and the energy production. Therefore, the effect blinds' angles is studied to reach an integrated and optimal situation.

\section{Blinds' angles and workplane illuminance}

Using the traditional methods to measure light flux among surfaces needs calculating the angular and geometrical factors among all radiating surfaces in the space. When the blinds are used with a high number of slats on windows, a great number of reflecting surfaces with a high number of angular factors among these surfaces and the work plane need to be calculated.

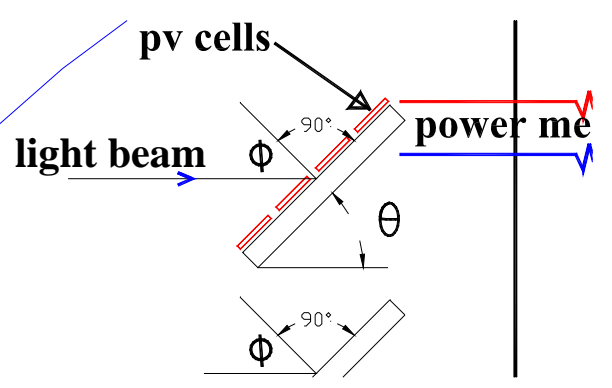

Figure 1. An explanation for all angles affecting the generated energy from the photocells.

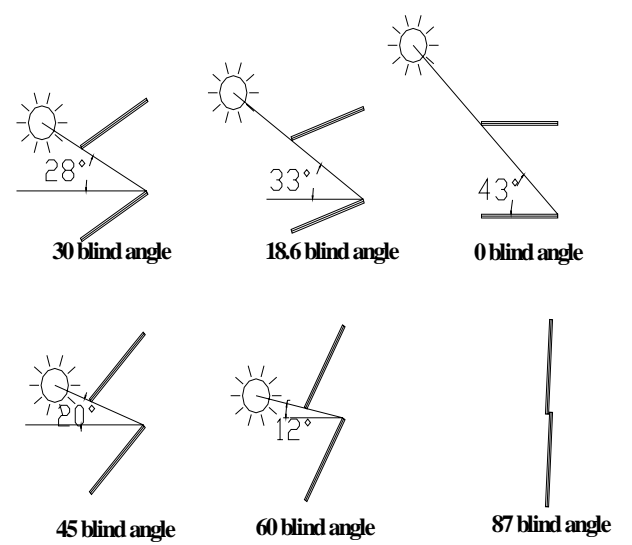

Figure 2. The minimum solar profile that covers the entire photocell for different blind angles.

Practically speaking, it is hard to divide the blinds into small pixels and estimate the angular factor for every pixel. In reality, a point at workplane receives light from the blinds' slats with different angular factors. Changing blinds' angles creates a new situation with new angular and geometrical factors; this eventually affects the illuminance level on the workplane.

The sum of all reflected light from the blinds' surfaces on the workplane is a function of blinds' angle change; at the same time this light comes from the blinds in different directions and is impractical to be calculated accurately (Fig. 4). Therefore, it was necessary to conduct lighting experiments to estimate the total illumination reflected from the blinds on the workplane.

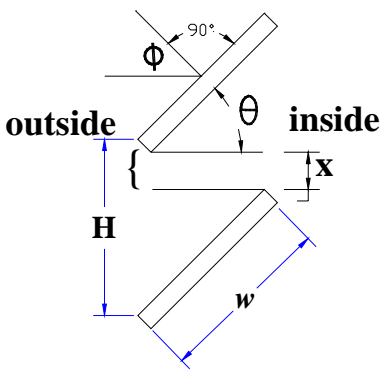

Figure 3. The relation between blind angles and the area between blinds' slats. 


\section{Research methods}

The study adopted two research approaches; for lighting measurements, an experimental strategy was used in a full-scale physical model. For photovoltaic cells' performance, a computational approach was used and compared with a number of actual measurements for electrical currents and voltages.

\section{A. Experimentation}

The main objectives of the lighting experiments were as follows:

1 Estimate the effect of blinds on horizontal workplane illuminance level;

2 Measure the effect of blinds on illuminance level at different distances from the window;

3 Estimate the relation between the vertical illuminance level outside the blinds and the vertical illuminance level inside the blinds;

4 Measure the change in illuminance level on vertical surfaces with blinds' angle change;

5 Measure the effect of wall reflections on the workplane illuminance level; and

6 Estimate the effect of the outside illuminance level change on workplane illuminance level.

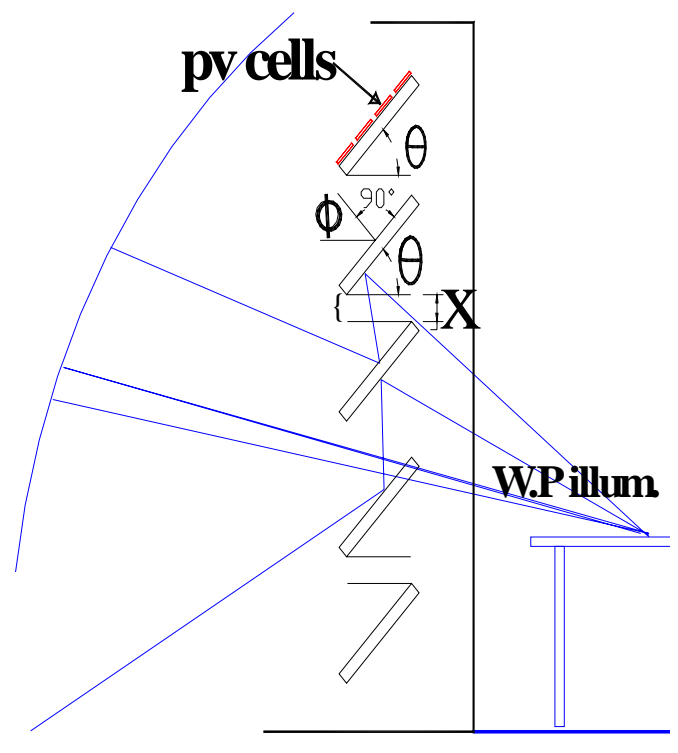

Figure 4. The effect of blind angles on light flux on the workplane illuminance level.

To achieve the aforementioned objectives, a full-scale model was built in the city of Dexter, Michigan (lat. $=42$, long. = 83). The model was $12 \mathrm{ft} \times 9 \mathrm{ft} \times 8 \mathrm{ft}$ and had one window, $3.5 \mathrm{ft} \times 3.5 \mathrm{ft}$, located in the southern side. The blinds were placed on the window outside the glass and the transmittance factor of the glass was 0.90 . The walls and the ceiling had the same finishing material. The blinds were made of white wood with a reflection of $60 \%$; they consisted of 2 inch-wide slats with 2 inches of space between every two slats (Fig. 5).

The workplane reference point was located $7 \mathrm{ft}$ from the window and $4.5 \mathrm{ft}$ from the two sidewalls of the office. Other reference points were located 20 inches apart at the midline
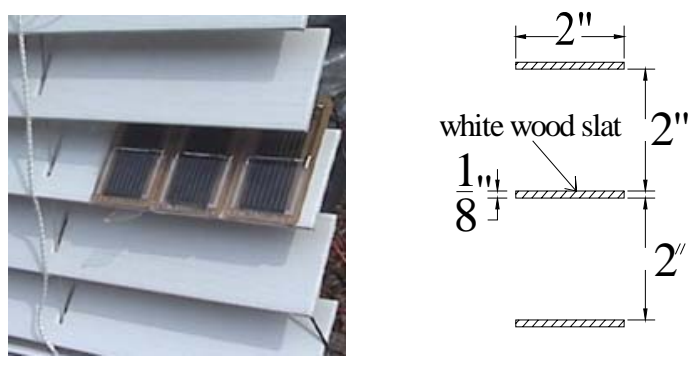

Figure 5. Details of the blind's type used in the lighting experiment. from the window to the opposite wall (Fig. 6 and Fig. 7).

The measurements were taken at all reference points (Fig. 8) by light sensors. The purpose of these measurements was to find the mathematical relation between the illuminance level at ref. point A and the other ref. points at B, C, D, E, and W (Fig. 9).

\section{B. Computation}

A computational method was used to estimate the generated power from the photovoltaic cells. In this method it was assumed that the photovoltaic efficiency is 18 percent $^{4}$.

As the generated power depends on the amount of solar insolation, the air mass effect on the solar energy attenuation was estimated by the following equation:

$$
\text { Ameff }=-0.334 \ln (1 / \sin \beta)+1.0
$$

\footnotetext{
${ }^{4}$ M.A. Green, “Recent Developments in Photovoltaic”, Solar Energy Vol. 76,2004, pp. 3-8
} 
The above equation was derived from the solar data in ASHRAE handbooks ${ }^{5}$. This equation gives the amount of solar attenuation relative to solar insolation when the solar altitude is 90 . The direct solar radiation on the ground was assumed to be $1000 \mathrm{~W} / \mathrm{m}^{2}$.[ Harries, 1985] $]^{6}$. The generated power and the total energy production from the photovoltaic cells were calculated by the following equations:

$$
\text { Pow }(\mathrm{t})=0.18 \mathrm{x} \text { Io } \mathrm{XAX} \cos (\Phi) \mathrm{x} \text { Ameff }
$$

$$
\mathrm{E}(\mathrm{t})=\int_{t_{2}}^{t_{1}} 0.18 \mathrm{x} I o \mathrm{X} A \mathrm{X} \cos (\Phi) \mathrm{X} \text { Ameff } . d t
$$
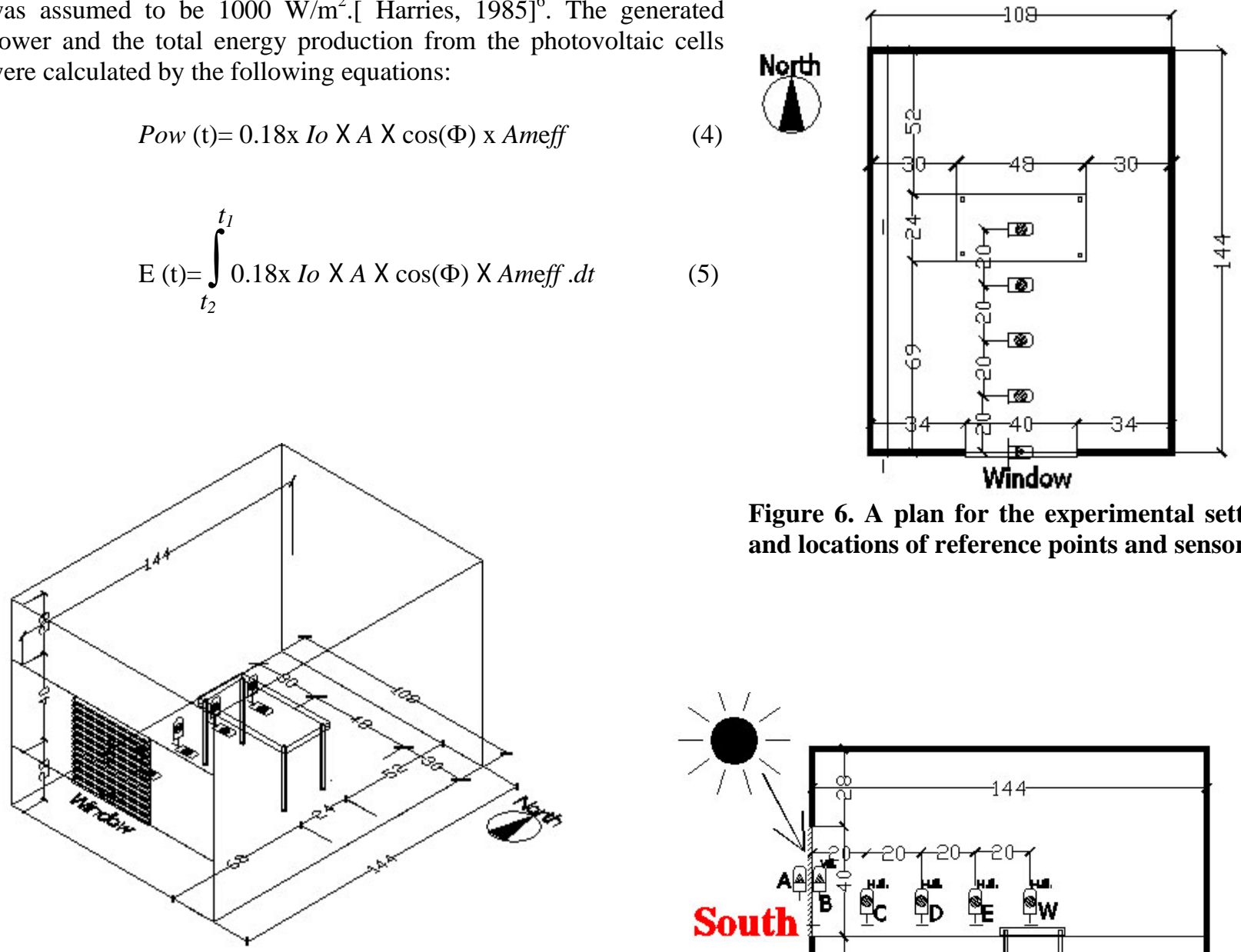

Figure 7. A general view for the experimental setting used for lighting measurements.
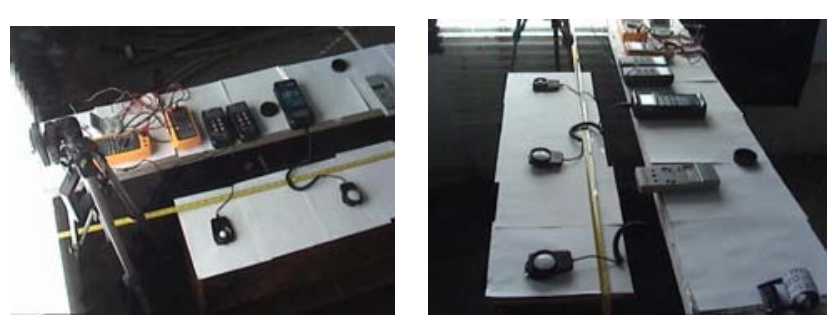

Figure 9. Light meters and sensors used to measure light level in the experiment full-scale mock-up.

Figure 6. A plan for the experimental setting and locations of reference points and sensors.

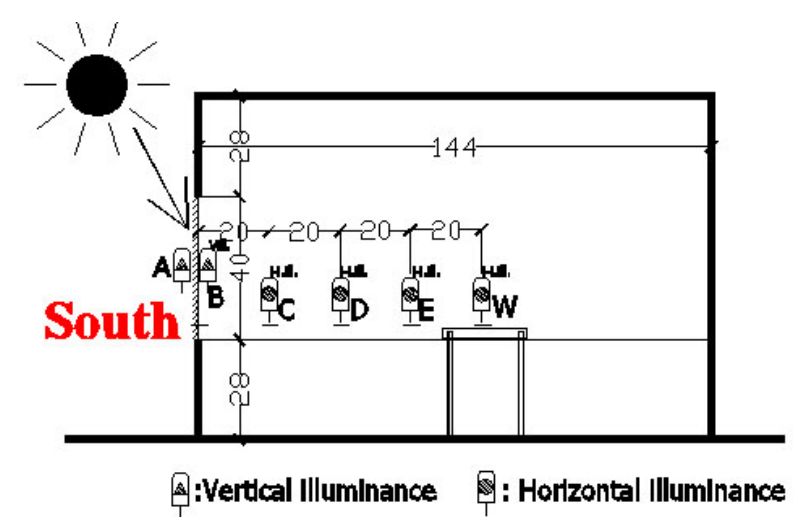

Figure 8. The reference points in the experimental setting,

A: Outside vertical illuminance level,

B: Average illuminance level 2 inches inside blinds,

C: Horizontal Illuminance at 20 inches from window,

D: Horizontal Illuminance at $\mathbf{4 0}$ inches from window,

E: Horizontal Illuminance at 60 inches from window

W: Horizontal Illuminance at workplane 80 inches from window.

\footnotetext{
${ }^{5}$ ASHRAE, Faye C. McQuiston, P.E. and Jeffrey D. Spitler, P.E., Cooling and Heating Load Calculation Manual, second edition, Atlanta, 1992.

${ }^{6}$ Harris, Miller Thomas, Solar Energy Systems Design, John Wiley and Sons, NewYork, 1985, pp. 137.
} 


\section{The experimental results and analyses}

The following section discusses the experimental results for lighting and photovoltaic energy computation

\section{A. Lighting results}

The experiments showed a strong mathematical correlation between the blinds' angle changes (see Fig. 10 and Fig. 11). The results included the vertical outside illuminance level with the blinds' angles and different distances from the window as in the following equation:

$$
E W=0.95 \mathrm{e}^{-0.038 \theta} 0.17\left(-3 \times 10^{-5} E_{A}^{2}+0.58 E_{A}\right) 0.97 e^{-1.1829 d-5}
$$

To find the value of blinds' angle when the workplane is known, Eq. (6) is rewritten as follows:

$$
\theta=-26.3 \ln \left[\frac{E W}{0.157\left(-3 X 10^{-5} \boldsymbol{E}_{A}{ }^{2}+0.58 \boldsymbol{E}_{A}\right) \boldsymbol{e}^{-1.1829 d-0.5}}\right]
$$

\section{B. Photovoltaic results}

The energy production from the photovoltaic cells placed on the blinds was estimated for each blinds' angle as a function of time during the day.

As the solar altitude is different from season to another, the blinds' angles performances were estimated for the summer and winter seasons.

When the solar altitude is higher, the percentage of obstructed areas of the PV cells on the slats becomes greater. This caused different results between the energy production in June $21^{\text {st }}$ and that in December $21^{\text {st }}$ (Fig. 12 and Fig. 13).

The power from the photovoltaic cells for one slat was estimated as a function of time for winter and summer as follows:

1. The power in June $21^{\text {st }}$

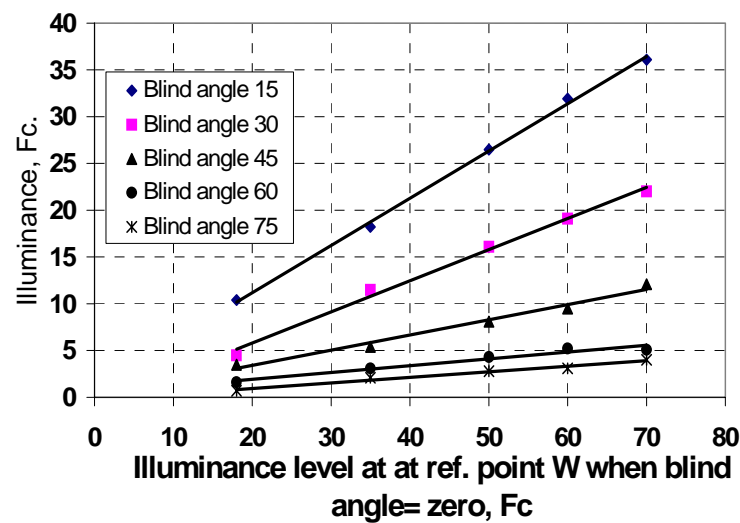

Figure 10. The relation between the illuminance at ref. point $W$, when the blind angle is zero, and the illuminance at the same ref. point with different blind angles.

$$
\begin{aligned}
& \text { Blinds' angle 0, Pow }=0.05 \mathrm{t}^{4}-0.4 \mathrm{t}^{3}+0.75 \mathrm{t}^{2}+1.4 \mathrm{t}+2.7 \\
& \text { Blinds' angle 18.6, Pow }=.04 \mathrm{t}^{3}-0.67 \mathrm{t}^{2}+2.6 \mathrm{t}+2 \\
& \text { Blinds' angle 30, Pow }=0.03 \mathrm{t}^{3}-0.56 \mathrm{t}^{2}+2.3 \mathrm{t}+1.8 \\
& \text { Blinds' angle 45, Pow }=0.02 \mathrm{t}^{3}-0.4 \mathrm{t}^{2}+1.9 \mathrm{t}+1.1 \\
& \text { Blinds' angle 60, Pow }=0.01 t^{3}-0.3 t^{2}+1.5 t+0.54
\end{aligned}
$$

2. The power in December $21^{\text {st }}$

$$
\begin{array}{ll}
\text { Blinds' angle 0, } & \text { Pow }=-0.06 \mathrm{t}^{3}+0.5 \mathrm{t}^{2}-0.6 \mathrm{t}+0.7 \\
\text { Blinds' angle 18.6, } & \text { Pow }=-0.1 \mathrm{t}^{3}+0.8 \mathrm{t}^{2}-0.74 \mathrm{t}+0.6 \\
\text { Blinds' angle 30, } & \text { Pow }=-0.15 \mathrm{t}^{3}+1.1 \mathrm{t}^{2}-0.8 \mathrm{t}+0.6
\end{array}
$$




$$
\begin{array}{ll}
\text { Blinds' angle 45, } & \text { Pow }=-0.15 \mathrm{t}^{3}+1.18 \mathrm{t}^{2}-0.9 \mathrm{t}+0.6 \\
\text { Blinds' angle 60, } & \text { Pow }=-0.15 \mathrm{t}^{3}+1.1 \mathrm{t}^{2}-0.67 \mathrm{t}+0.6
\end{array}
$$

\section{Optimization}

The above-mentioned equations were employed to find the optimal blinds' angles. The optimization process took into account many conditions that should exist in any indoor environment as follows:

1-No direct sunlight strikes the workplane.

2- Energy production maximized

3-Illuminance level maintained between 50 and $250 \mathrm{Fc}$.

Given these three conditions, the daytime hours from 9 am to 5 pm was divided into five periods in order to estimate the optimal angles.

For every time period, a minimum and maximum blinds' angle was estimated. The minimum blinds' angle maintains the illuminance level above $50 \mathrm{Fc}$, whereas the maximum blinds' angle maintains the indoor level below $250 \mathrm{Fc}$.

The blinds' angles that produce maximum energy were also estimated for each time period and checked to ensure that they lie within the acceptable range of optimal blinds' angles for lighting (Fig. 14).

For the visual criteria, an office drawing similar to the experimental setting was tested using blinds with angles 0 to $15,30,45$, and 60 . The simulation was performed by RADIANCE software for lighting analyses. The major concern in this simulation was to make sure that the sunlight does not go through the blinds and causes discomfort glare (Fig. 15).

The optimal angles were estimated based upon the above criteria for the $21^{\text {st }}$ day of each month in the year (Fig. 16). For practical handling of the optimality curves, the mathematical relations were developed for each month as follows:

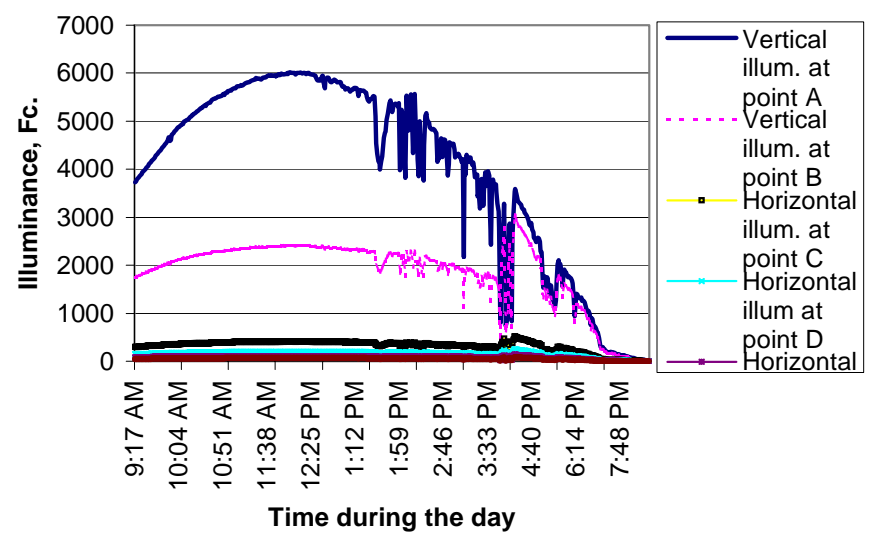

Fig. 11 Lighting readings at the reference points of lighting experiments on August $1^{\text {st }}, 2004$.

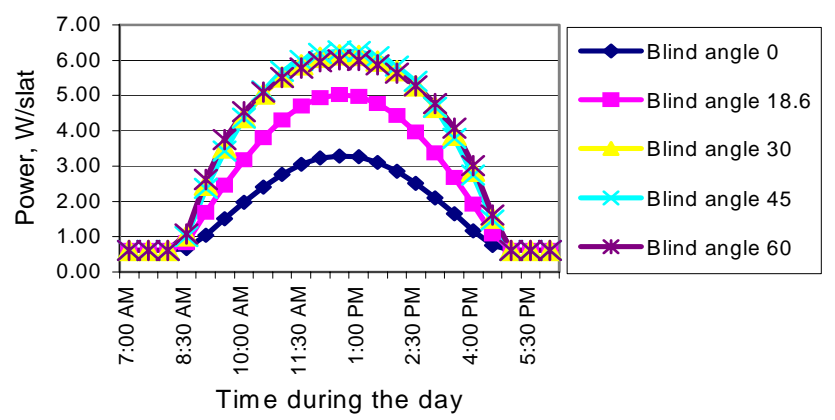

Fig. 12 The generated power from the PV cells for one slat of blinds on December $21^{\text {st }}$.

$\begin{array}{ll}\text { OBA (Dec 21) } & =-0.075 \mathrm{t}^{4}+1.6 \mathrm{t}^{3}-14 \mathrm{t}^{2}+54 \mathrm{t}-57 \\ \text { OBA (Jan 21) } & =-0.062 \mathrm{t}^{4}+1.3 \mathrm{t}^{3}-10 \mathrm{t}^{2}+39 \mathrm{t}-32 \\ \text { OBA (Feb 21) } & =-0.037 \mathrm{t}^{4}+0.78 \mathrm{t}^{3}-6.5 \mathrm{t}^{2}+25 \mathrm{t}-13 \\ \text { OBA (Mar21) } & =-0.0088 \mathrm{t}^{5}+0.21 \mathrm{t}^{4}-1.8 \mathrm{t}^{3}+5.4 \mathrm{t}^{2}+2.3 \mathrm{t}-1.2 \\ \text { OBA (April 21) } & =0.0 \mathrm{t} \\ \text { OBA (May 21) } & =0.0 \mathrm{t} \\ \text { OBA (June 21) } & =0.0 \mathrm{t}\end{array}$




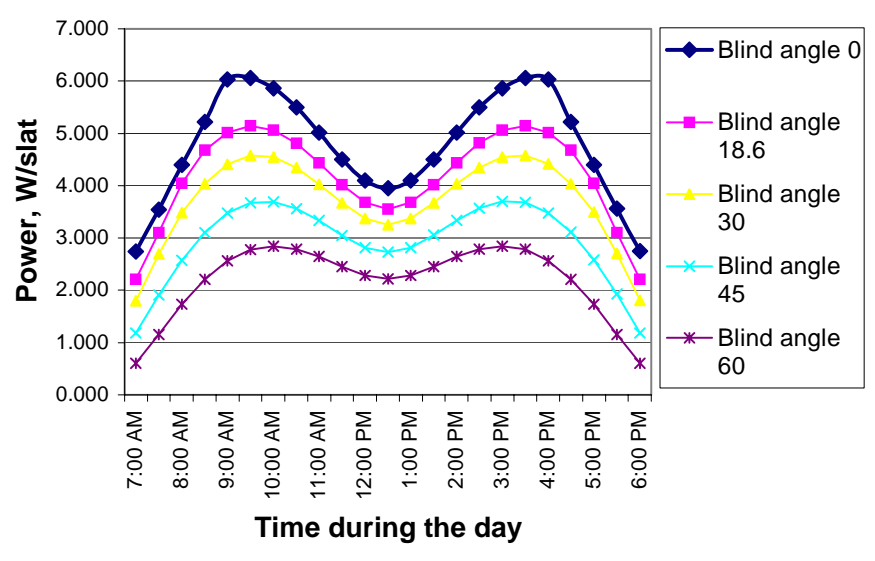

Fig. 13 The generated energy by photovoltaic cells placed on a slat one meter in length on June $21^{\text {st }}$.

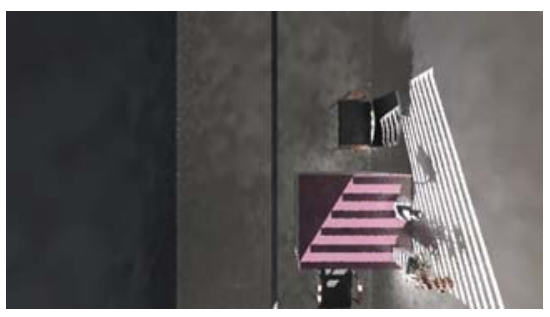

A

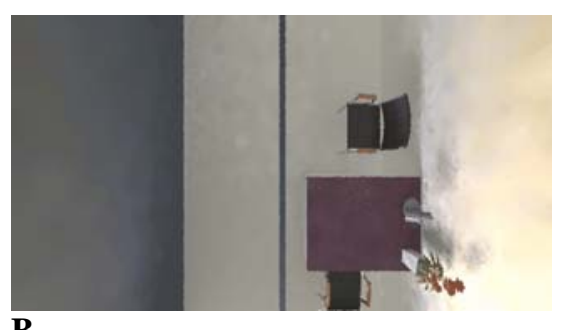

B

Fig. 15 The effect of blind angles on human visual comfort,

A: light distribution in an office with discomfort glare resulted from nonoptimal blind, B: light distribution in an office without glare resulted from optimal blind angle, simulated by RADIANCE software.

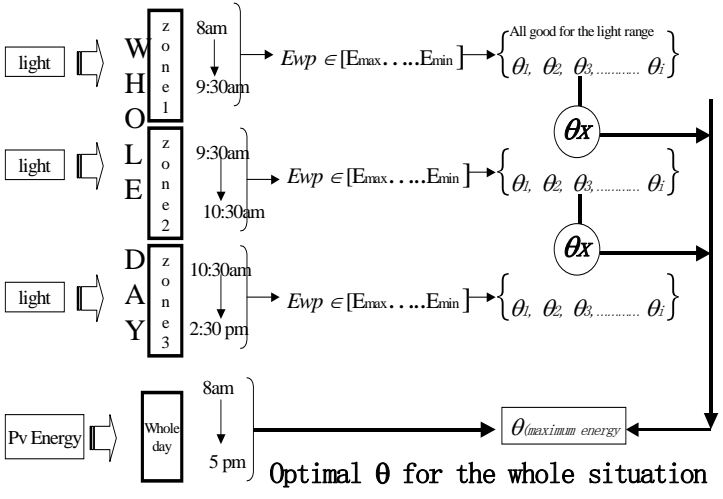

Fig.14 The optimizing process among lighting, heat gain, and generated energy from PV cells.

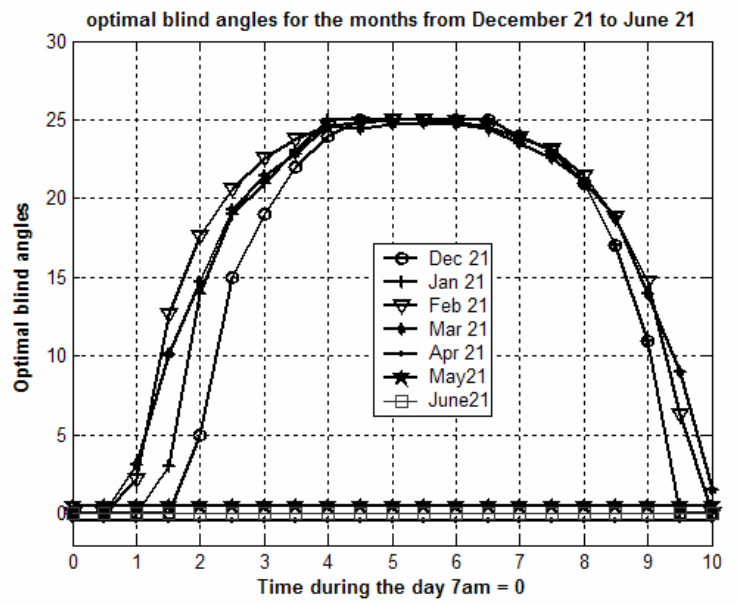

Fig. 16 Optimal blind angles estimated based on the parameters of the experimental setting. 


\section{Coding}

For the purpose of general applicability, the results of optimization and energy production were coded using Java programming language. The code was written to deal with generic locations and different weather conditions.

The users of this code need to input the weather data, geographical data, and space geometry. The output of this program is the optimal angles that maintain the indoor lighting within the acceptable range and maximize the energy production from the photovoltaic cells.

The logic of this code acts within the requirement of the optimality giving first priority to the indoor light level. It works with nested loops and if statements logic. The outer loop of the whole cycle is for indoor lighting that is bounded by minimum and maximum values of 50 and $250 \mathrm{Fc}$ respectively. If the lighting conditions in the space are fulfilled, the second loop starts searching optimal blinds' angles for energy production from the photovoltaic cells (Fig. 17).

The output of this code takes graphical and textual format; the text format could be saved in Excel, WinWord, or txt format (Fig. 18, Fig. 19, Fig. 20, and Fig. 21).

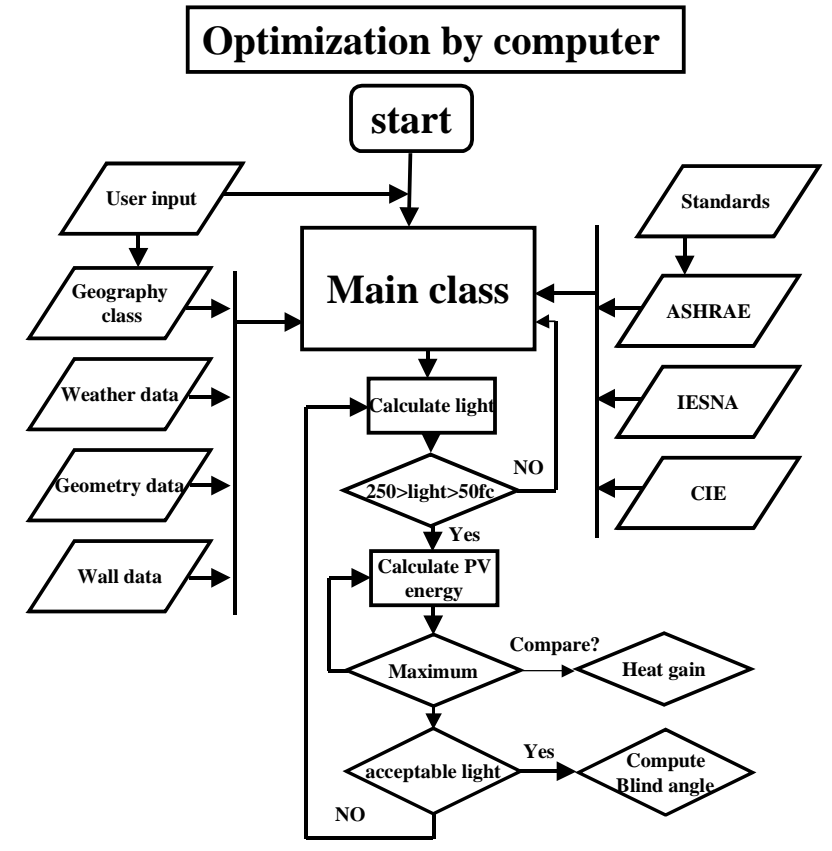

Fig. 17 Optimization method used in writing the computer code.

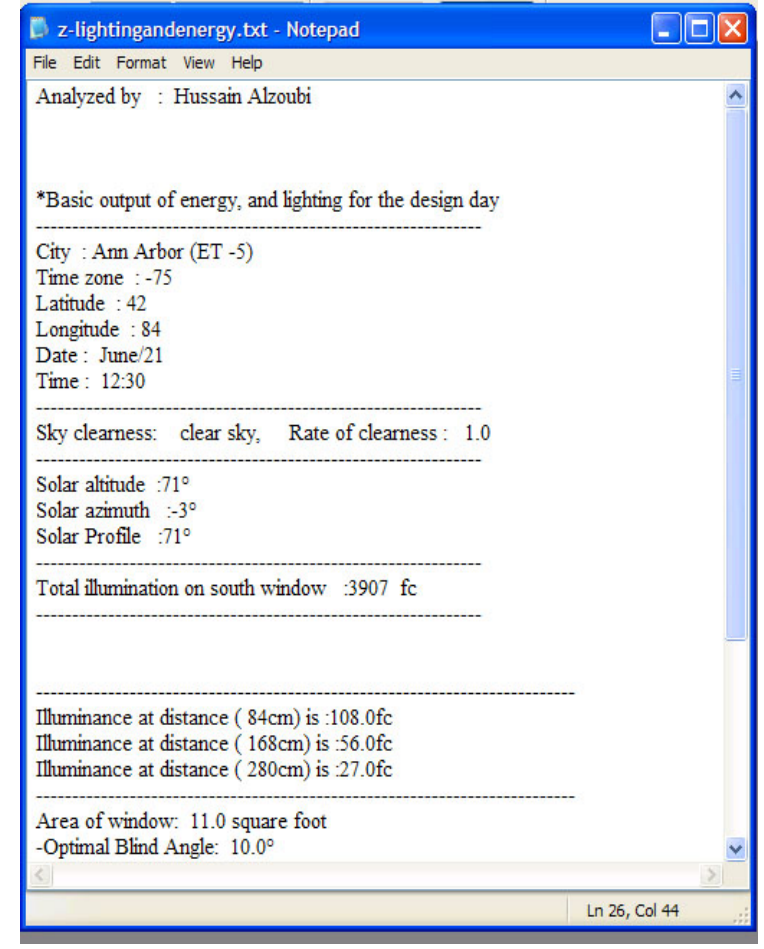

Fig. 18 A sample of output text file produced by the computer code designed for optimization. 


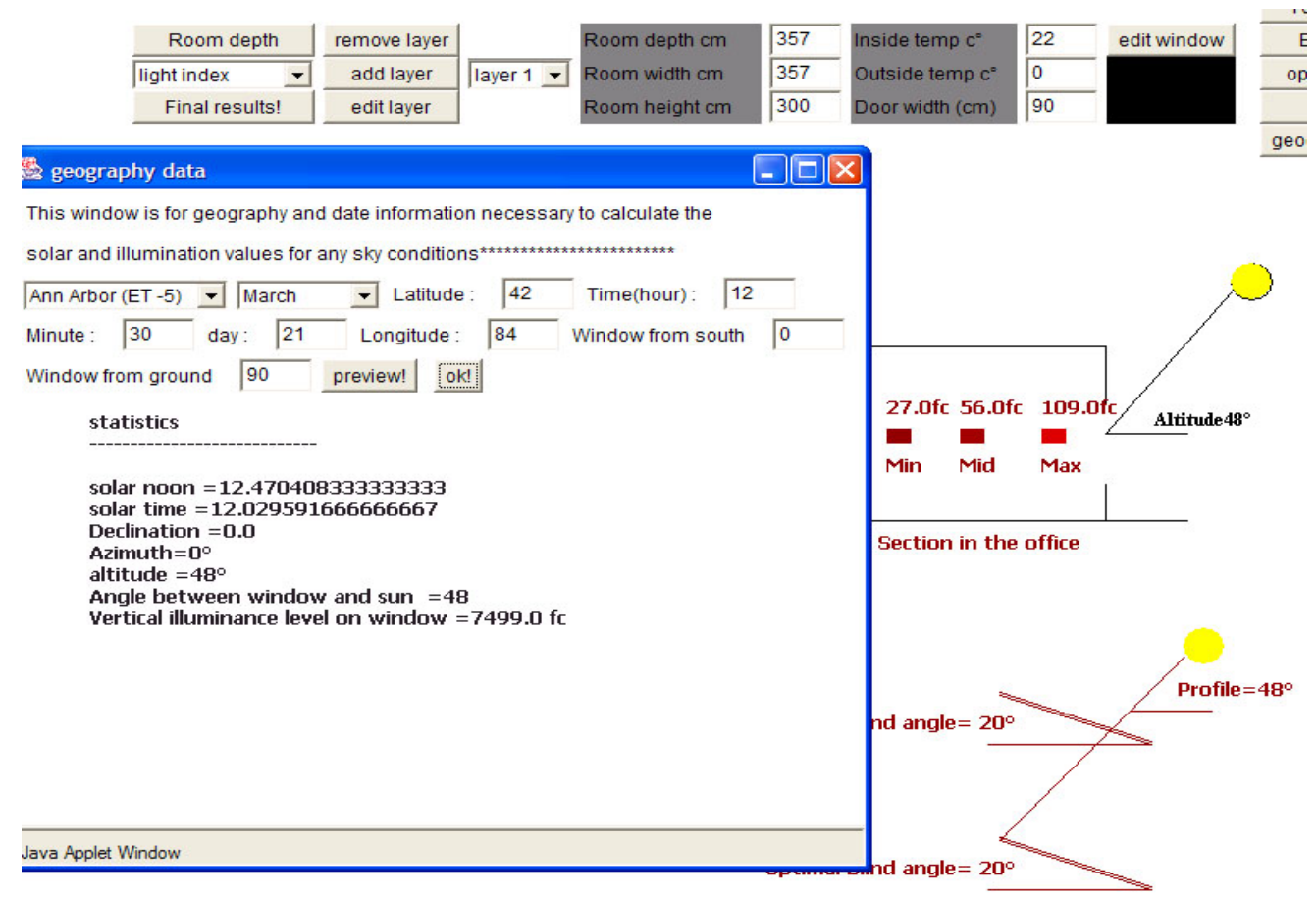

Fig. 19 An example of calling the geometry class through the main class in the optimization code.

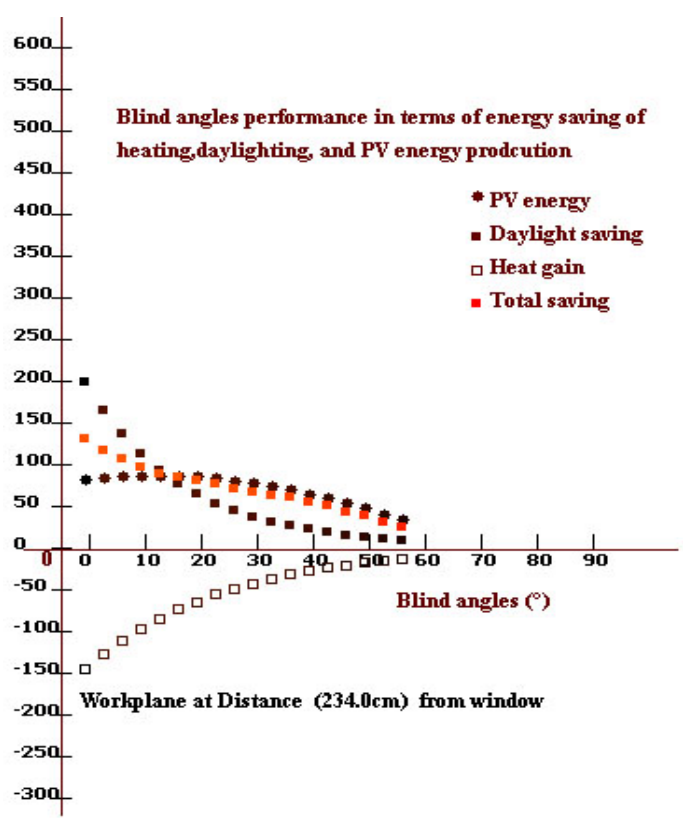

Fig. 20 Total energy saving calculated and drawn by the written computer code.

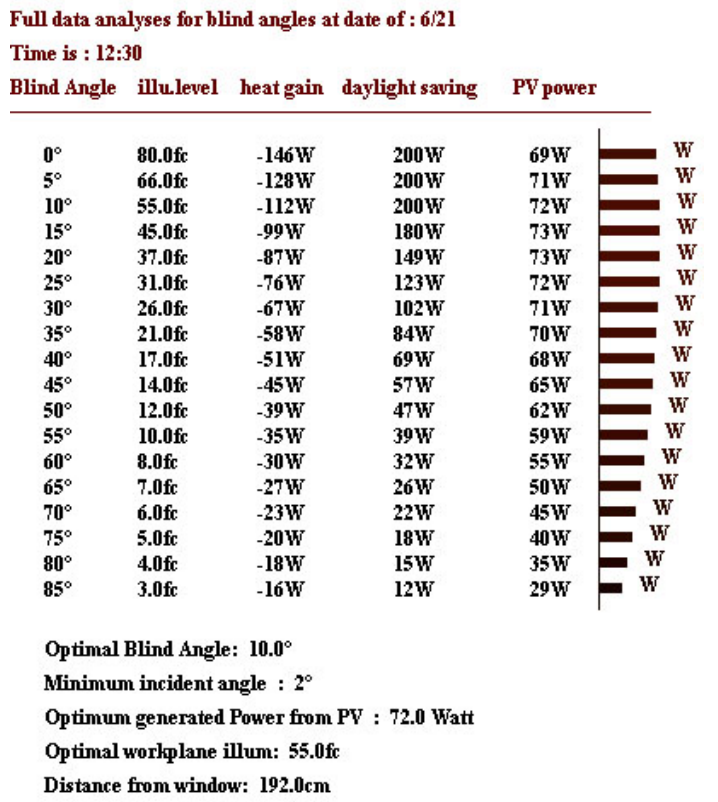

Fig. 21 Computed optimal angles and related generated power estimated by the written computer code. 


\section{Control system and automation}

\section{A. Description}

The algorithm used in the mentioned java code has been utilized in creating a control system programmed by C language. The system used the lighting formulas developed and derived from the experimental results to motorize the blind automatically.

The system consists of Ezio electrical board with suitable type of microchips, five major sensors for lighting, temperature, and photovoltaic cells. The system with all its components is attached with a pc to record the system data and save it in text or Excel format (Fig. 22). In this system, the blinds are sandwiched between two glass layers. The photovoltaic cells are placed on the slats of the blinds (Fig. 23). Two fans are placed on an outlet and inlet at the designed glass box containing the blinds. A 12-volt DC motor is geared with the blinds at one end; at the other end of the blind a potentiometer is attached to indicate the angle of the blinds.

\section{B. The system's behavior}

As mentioned above, the system uses five major sensors as input to the main Ezio board that controls the motor movement based upon the signals from the sensors. The lighting sensors send the light readings to the main controller in the Ezio board. If the light is below $50 \mathrm{Fc}$, the blinds stay at zero angle to allow as much light as possible getting into the space. As long as the internal light is between 50 and $250 \mathrm{Fc}$, the system starts finding the most optimal angle that maximizes the energy generated from the photovoltaic cells placed on the blinds.

The thermal sensor sends the temperature reading to the main Ezio board to determine the direction of the fans on the glass box. If the building is in the heating mode, the warm air trapped in the glass box will be blown into the space. Otherwise, if the building is in cooling mode, the warm air is kicked out of the glass box.

\section{The system's performance}

The system was tested in an actual office to validate the experimental results under similar conditions. The performance of this system was very similar to the predicted results. The optimal blinds' angles calibrated by the system were very close to the computed blinds' angles from the experimental results (Fig. 24). The system was also tested to measure the generated voltage from the photovoltaic cells placed on the blinds under two different conditions: the first case was estimated with fixed blinds and the other was estimated with automated blinds. The generated power by the automated blinds is higher than that generated by fixed blinds by 20 to 40 percent depending on the time during the day.

Theoretically, this system makes the angle between the normal of the photovoltaic cells and the solar altitude as small as possible. The movement of the blinds happens only if the internal light is enough and within the acceptable range. A theoretical comparison between the control system and fixed blinds at angle zero was conducted to estimate the difference in power production from the photovoltaic cells ( see Fig. 25)

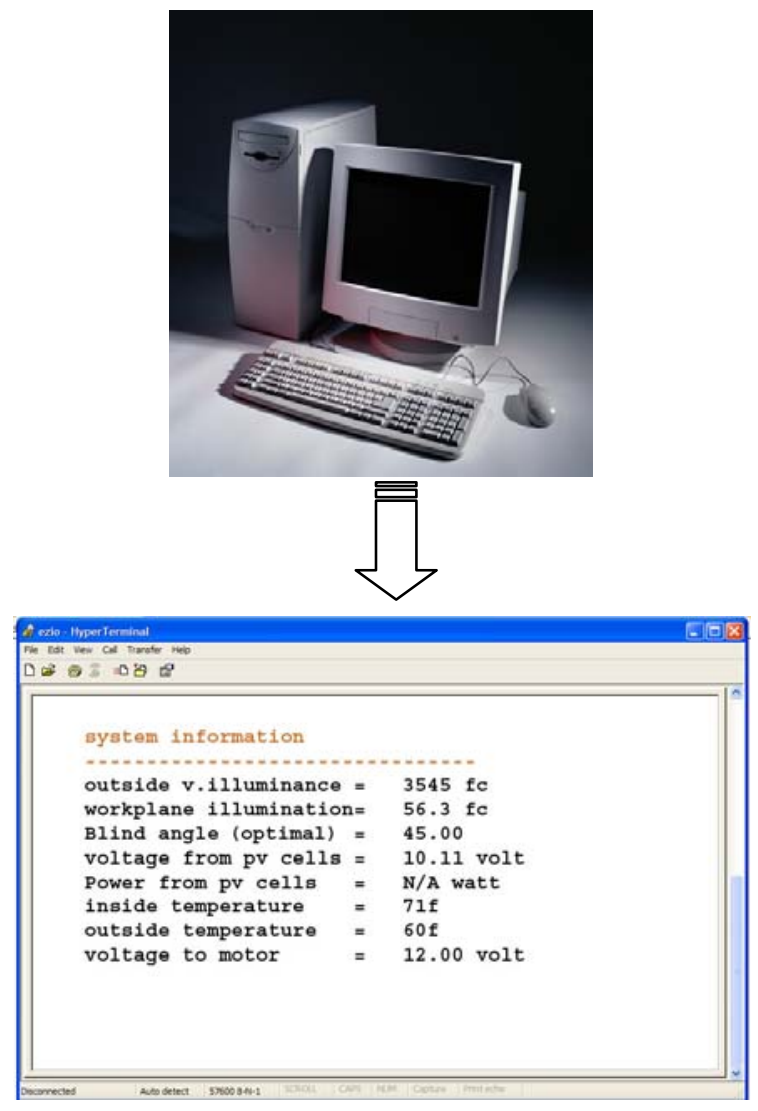

Fig. 22 System's output on a monitor with hyper terminal screen. 


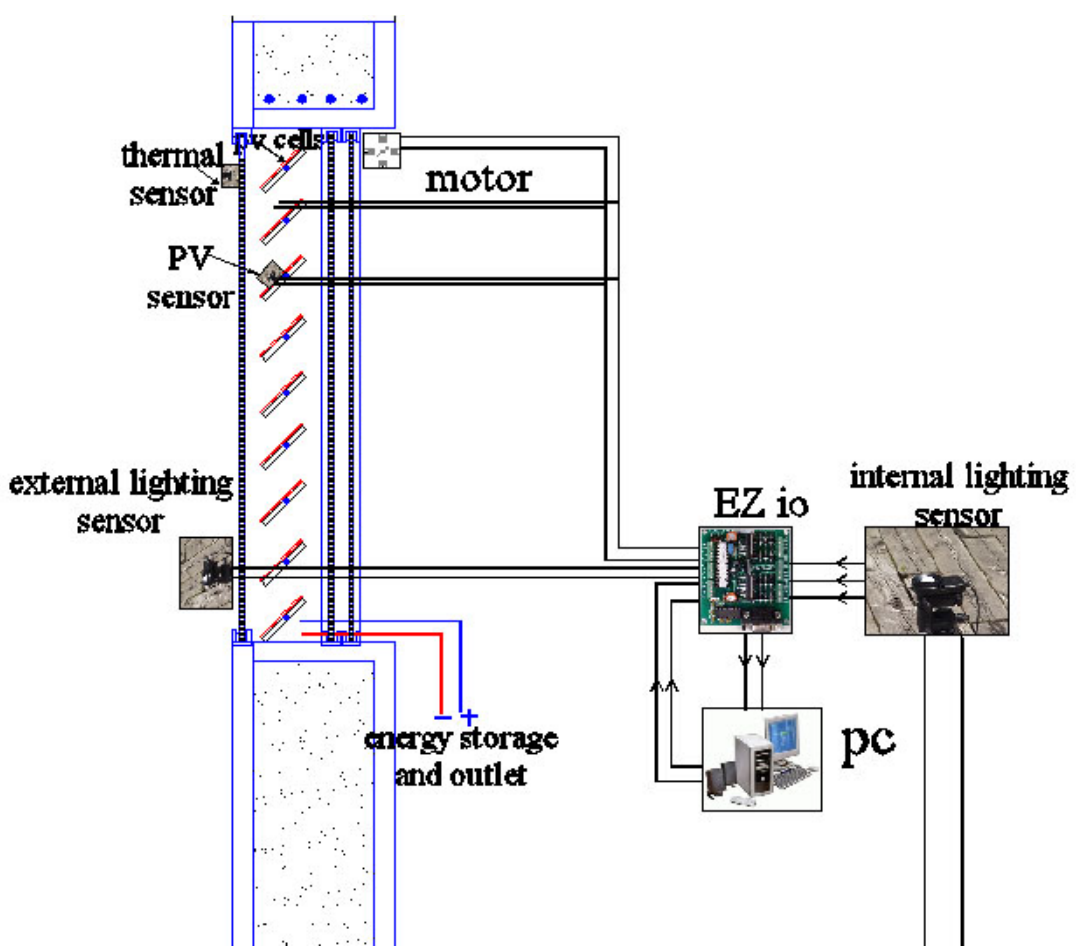

Fig. 23 A section in the control system with its major components.

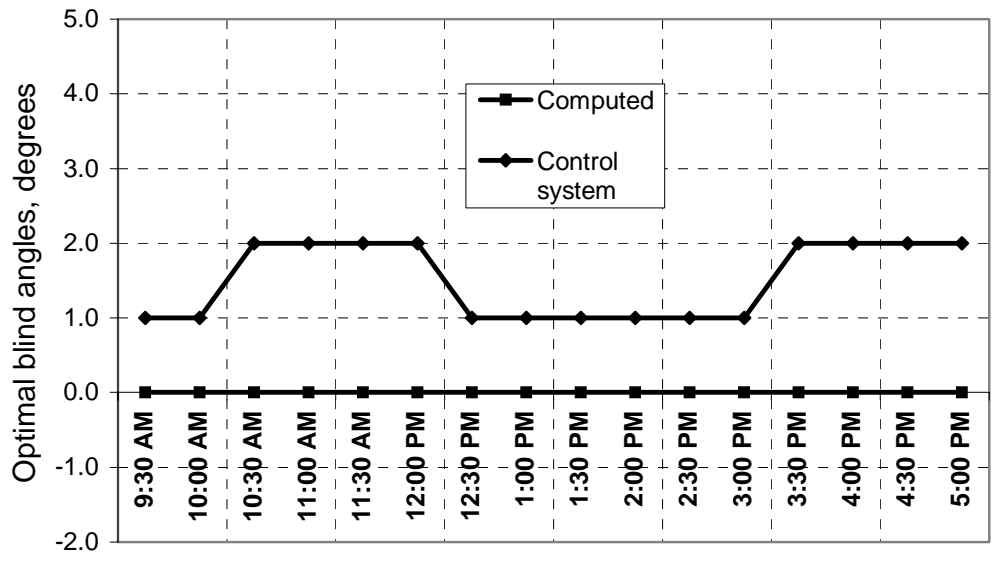

Time during the day

Fig. 24 A comparison between the optimal blind angles determined by the control system and computer on May 28 ${ }^{\text {th }}, 2005$. 


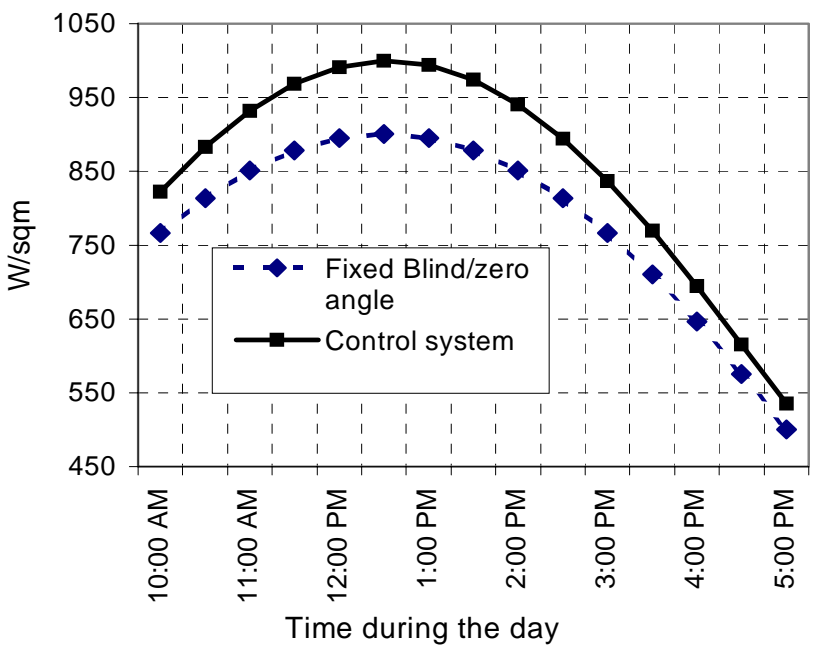

Fig. 25 Theoretical comparisons between the generated power by the computer and the control system.

\section{Conclusions}

The study explored the idea of integrity in building facades' performance. It showed that optimization for lighting and energy production is possible if the blinds' angles are well adjusted to meet this goal. Automated blinds can substitute the manual solutions for blinds' adjustments.

The designed control system can adjust the blinds' angle within accuracy of \pm 2 degrees compared to the manual solutions. As the experiments of this study were conducted under specific conditions, the control system presents a more flexible method to deal with generic locations in the world; it can handle any instantaneous situation as it reads the light every 0.5 second.

The power generated at noon by the control system exceeds that generated by fixed blinds' angles at angle zero degrees by almost $100 \mathrm{~W} / \mathrm{m}^{2}$. This difference reaches $400 \mathrm{~W} / \mathrm{m}^{2}$ when the blinds tilted at angle $45^{\circ}$.

It should be known that the energy produced by the optimal angles is affected by keeping the indoor light within the acceptable range. The energy production becomes higher if it is not integrated with the indoor light level.

\section{Acknowledgments}

I would like to thank the Doctoral Program in Architectural at the University of Michigan for the great support and assistance. Special thanks to the chair of the doctoral program, Professor Jean Wineman, for the great support during the time of this research. I would also like to acknowledge the generous financial support from Rackham, the graduate school at the University of Michigan. 


\section{References}

${ }^{1}$ Kwang-Wook Park , Andreas K.Athienitis, "Workplane Illuminance Prediction Method for Daylighting Control Systems,” Solar Energy, Vol. 75, 2003, pp. 277 -284.

${ }^{2}$ Cheol-Soo Park, Godfried Augenbroe, Tahar Messadi, "Daylighting Optimization in Smart Façade Systems," Eighth International IBPSA Conference, Eindhoven, Netherlands August 11-14, 2003, pp. 1001-1008.

${ }^{3}$ Takashi Inoue, "Solar Shading and Daylighting by Means of Autonomous Responsive Dimming Glass: practical application,” Energy and buildings, Vol. 35, 2003, pp. 463-471.

${ }^{4}$ M.A. Green, “Recent Developments in Photovoltaic”, Solar Energy Vol. 76, 2004, pp. 3-8

${ }^{5}$ ASHRAE, Faye C. McQuiston, P.E. and Jeffrey D. Spitler, P.E., Cooling and Heating Load Calculation Manual, second edition, Atlanta, 1992.

${ }^{6}$ Harris, Miller Thomas, Solar Energy Systems Design, John Wiley and Sons, NewYork, 1985, pp. 137. 